\title{
Períodos de Dessecação de Urochloa ruziziensis e SeU Reflexo NA PRodutividade DA SoJa RR ${ }^{1}$
}

\author{
Burn-down Timing of Urochloa ruziziensis and its Effect on RR Soybean Yield
}

\author{
NEPOMUCENO, M.P. ${ }^{2}$, VARELA, R.M. ${ }^{3}$, ALVES, P.L.C.A. ${ }^{4}$ e MARTINS, J.V.F. ${ }^{5}$
}

\begin{abstract}
RESUMO - Com o objetivo de avaliar os efeitos de periodos de dessecação de Urochloa ruziziensis na implantação e na produtividade da soja transgênica no sistema de plantio direto, foram conduzidos dois experimentos em campo, nos municipios de Colina-SP, no ano agrícola de 2007/08, e Jaboticabal-SP, em 2009/10. Em Colina, utilizou-se uma área de pastagem de $U$.ruziziensis, conduzida há sete anos. Nesse local foram testados quatro períodos de dessecação da cobertura vegetal: 30,20, 10 e 0 dias antes da semeadura da soja. No experimento de Jaboticabal, a área utilizada tinha histórico de pastagem com U. ruziziensis, que no ano agrícola 2008/09 foi cultivada com milho. Após a colheita do milho ocorreu reinfestação natural de U. ruziziensis na área, correspondendo a mais de $80 \%$ de cobertura vegetal. Nesse experimento, os tratamentos corresponderam a seis periodos de dessecação: $25,20,16,12,7$ e 0 dias após a aplicação. Nos dois experimentos utilizou-se 1,44 kg e.a. ha-1 do herbicida glyphosate e o cultivar de soja M-SOY 7908 RR. O delineamento experimental foi o de blocos ao acaso, com quatro repetições. Foram avaliados o estande da cultura aos 20 dias após a semeadura da soja e na pré-colheita, a altura de plantas, a altura de inserção da primeira vagem, o número de vagens por planta e o rendimento de grãos (produtividade estimada em $\mathrm{kg} \mathrm{ha}^{-1}$ ). Os resultados foram submetidos à análise de variância (teste $\mathrm{F}$ ), com as médias sendo comparadas pelo teste de Tukey a $5 \%$ de probabilidade. A dessecação de U. ruziziensis no mesmo dia da semeadura da soja reduziu a altura das plantas, o número de vagens por planta e a produtividade de grãos. O período recomendado para o manejo químico de U. ruziziensis com glyphosate está entre 10 e 20 dias antes da semeadura da soja. Pôde-se concluir que o periodo de dessecação de U. ruziziensis alterou a produtividade da cultura.
\end{abstract}

Palavras-chave: Brachiaria ruziziensis, Glycine max, cobertura vegetal, alelopatia, glyphosate.

\begin{abstract}
Two field trials were carried out to evaluate the effects of burn-down timing of Urochloa ruziziensis on transgenic soybean establishment and yield under the no-tillage system. One experiment was conducted in Colina, SP - Brazil, in 2007/2008 season, and the other in Jaboticabal, SP Brazil, 2009/2010 season. In 2007/2008, the experiment was carried out in a 7-year-old grass pasture of $\boldsymbol{U}$. ruziziensis, with four burn-down timings of vegetation cover being tested 30,20 , 10 , and $O$ days in advance to soybean sowing. In 2009/2010, the experiment was conducted in an old grass pasture of $\boldsymbol{U}$. ruziziensis cropped with maize the summer before. After maize harvesting, a natural re-infestation of $\boldsymbol{U}$. ruziziensis occurred, corresponding to more than $80 \%$ of the vegetation cover. In this experiment, treatments corresponded to six burn-down timings of vegetation cover 25, $20,16,7$, and $O$ days in advance to soybean sowing. In all experiments, $1.44 \mathrm{~kg}$ a.e. ha-1 of herbicide glyphosate was applied, and the soybean cultivar M-SOY 7908 RR was used. The experiments were arranged in a randomized block design, with four replicates. The evaluations were carried out by measuring crop stand 20 days after sowing and pre-harvest, plant height, first pod insertion height, number of pods per plant, grain yield, and estimated yield. Data were submitted to ANOVA and the Tukey test at $5 \%$ of probability. Burn-down of $\boldsymbol{U}$. ruziziensis performed at the same day of crop sowing reduced plant height, number of pods per plant, and crop grain yield. Burn-down
\end{abstract}

Recebido para publicação em 3.4.2011 e aprovado em 25.4.2012.

2 Eng-Agra ., Pós-Doutoranda, Faculdade de Ciências Agronômicas e Veterinárias, Universidade Estadual Paulista "Julio de Mesquita Filho" -FCAV/UNESP, Jaboticabal-SP, <mariluce_n@hotmail.com>; 3 Professora Titular, Dep. de Química Orgânica, Universidade de Cádiz, Espanha <rosa.varela@uca.es>; ${ }^{4}$ Professor Adjunto, FCAV/UNESP, Jaboticabal-SP, Bolsista PQ, <plalves@fcav.unesp.br>; 5 Técnico, Laboratório de Plantas Daninhas, FCAV/UNESP, <Jaboticabal <martins@fcav.unesp.br>. 
timing of $\boldsymbol{U}$. ruziziensis $u$ sing glyphosate was recommended to be between 10 and 20 days in advance to crop sowing. In conclusion, soybean yield was affected by burn-down timing of $U$. ruziziensis.

Keywords: Brachiaria ruziziensis, Glycine max, vegetation cover, allelopathy, glyphosate

\section{INTRODUÇÃO}

As espécies do gênero Urochloa (syn. Brachiaria) são importantes forrageiras de regiões tropicais, como a África, Ásia, Austrália e América do Sul. Segundo Ferraz (2003), no Brasil há aproximadamente 95 milhões de hectares cultivados com espécies desse gênero.

O uso de plantas de cobertura é uma alternativa para aumentar a sustentabilidade dos sistemas agrícolas, podendo restituir quantidades consideráveis de nutrientes aos cultivos, uma vez que essas plantas absorvem nutrientes das camadas subsuperficiais do solo e os liberam, posteriormente, na camada superficial, pela decomposição dos seus resíduos (Duda et al., 2003).

De acordo com Bayer et al. (2006), em plantio direto é necessária a entrada de cerca de $4 \mathrm{mg} \mathrm{ha}^{-1}$ por ano de carbono no sistema para compensar a quantidade perdida na decomposição dos resíduos orgânicos, o que dificilmente é obtido com culturas anuais.

Oliveira et al. (2002), trabalhando com várias coberturas vegetais, constataram que o milheto, com produção de matéria seca acima de $14 \mathrm{t} \mathrm{ha}^{-1}$, propiciou a maior proteção ao solo, maior conservação da água e menor variação da temperatura do solo. Esses autores ressaltaram também que o maior acúmulo de macronutrientes e a relação $\mathrm{C} / \mathrm{N}$ alta dessa espécie possibilitaram maior tempo de permanência da palhada na superficie do solo, o que resultou em maior rendimento de grãos de feijão.

De maneira geral, as gramineas do gênero Urochloa estão sendo consideradas as principais opções na formação de palhada para o sistema de plantio direto, devido à alta relação $\mathrm{C} / \mathrm{N}$ em sua composição, relacionada com grandes concentrações de lignina, o que prolonga seu período de decomposição, e à boa produção de matéria seca. A palhada contribui na formação de uma camada espessa e uniforme de cobertura morta sobre o solo, constituindo-se em uma barreira física, auxiliando no controle de plantas daninhas.

As espécies forrageiras U. ruziziensis e $U$. decumbens, por se manterem em crescimento durante toda a estação seca e pela facilidade de dessecação, podem ser melhor aproveitadas com o propósito de cobertura do solo (Machado \& Assis, 2010). Entretanto, Nunes et al. (2006) ressalvam que para utilização da palhada com a função de cobertura do solo são necessárias informações que esclareçam sobre o período ideal entre a dessecação e a semeadura da cultura, para que esta não influencie negativamente a cultura em sucessão.

Torres et al. (2008), trabalhando com seis espécies de cobertura do solo (milheto, sorgo, crotálaria, aveia, Brachiaria e guandu), concluíram que a maior taxa de decomposição e liberação de nutrientes dessas coberturas ocorre aos 42 dias após a dessecação e que milheto e crotalária superaram $U$. brizantha quanto à produção de fitomassa. Menezes et al. (2009) concluíram que sorgo granífero, Brachiaria plantaginea e U. ruziziensis foram as espécies mais promissoras para produção de fitomassa. Em estudo conduzido por Muraishi et al. (2005), as forrageiras do gênero Urochloa apresentaram crescimento inicial mais lento e foram menos produtivas que espécies anuais, quando avaliadas em curtos intervalos (50 dias). No entanto, Pacheco et al. (2008), trabalhando com intervalos mais longos, durante toda a estação seca, observaram que as forrageiras desse gênero são mais produtivas que milheto e híbridos de sorgo forrageiro. Elas também são mais eficientes na supressão de plantas daninhas e resultam em maior produtividade de grãos de soja, quando utilizadas em sistemas de manejo que as empregam em sucessão à cultura de verão (Pacheco et al., 2008). 
Na dessecação das coberturas vegetais, um dos herbicidas mais utilizados é o glyphosate. Diversas doses de glyphosate têm sido testadas para obtenção de cobertura morta de diferentes plantas de cobertura. Em plantio direto sobre $U$. decumbens e $U$. brizantha, a Embrapa (2004) recomenda o período de 30 dias entre a dessecação de Brachiaria e a semeadura da soja, utilizando doses de 1,8 a 2,16 kg e.a. ha-1 de glyphosate.

Existem vários relatos de agricultores sobre sintomas de amarelecimento e redução no crescimento das plantas de soja, com consequente diminuição na produtividade de grãos, quando utilizam áreas provenientes de pastagem com Urochloa em sistema de plantio direto. Esse efeito é mais perceptível quando a semeadura da soja é feita imediatamente após a dessecação da cobertura vegetal. Os sintomas observados nas plantas de soja estão, provavelmente, relacionados com a quantidade de cobertura vegetal depositada sobre o solo, que impõe ao sistema ações físicas, químicas e biológicas, como, por exemplo, a alteração na dinâmica do carbono e do nitrogênio no solo, como também podem estar relacionados com a ação fitotóxica do herbicida utilizado na dessecação da cobertura vegetal. Além disso, a decomposição da cobertura vegetal resulta na produção e / ou liberação de compostos químicos que alteram o crescimento de plantas daninhas (Barnes \& Putnam, 1983), bem como podem prejudicar a cultura (Chou \& Patrick, 1976).

Nunes et al. (2009), para avaliar períodos de manejo químico de $U$. decumbens antecedendo o plantio direto da soja, verificaram que $8,6 \mathrm{t} \mathrm{ha}^{-1}$ de cobertura em vegetação nativa, após o manejo químico, representou uma camada de $15 \mathrm{~cm}$ de espessura sobre o solo.

Melhorança \& Vieira (1999) verificaram que o período de dessecação de $B$. decumbens afetou o rendimento e o desenvolvimento vegetativo da soja; a dessecação realizada 18 dias antes da semeadura propiciou rendimentos 17 e $32 \%$ superiores aos das dessecações realizadas aos 7 e 1 dias antes da semeadura, respectivamente.

Nesse contexto, objetivou-se avaliar em campo, em dois locais, efeitos dos períodos de dessecação de $U$. ruziziensis na implantação, no desenvolvimento e na produtividade de grãos de soja RR.

\section{MATERIAL E MÉTODOS}

Foram conduzidos dois experimentos em campo: um no município de Colina,-SP, no ano agrícola 2007/08, e outro em Jaboticabal-SP, em 2009/10. Em Colina, foi instalado em área de pastagem, implantada há sete anos com U. ruziziensis. Em Jaboticabal, utilizou-se uma área com histórico de pastagem dessa mesma graminea, que na safra anterior, de verão, foi cultivada com milho. Após a colheita do milho houve reinfestação de $U$. ruziziensis.

A amostragem para quantificar a cobertura vegetal, nos dois experimentos, foi realizada na pré-dessecação inicial de Urochloa, utilizando um quadro vazado de $1,0 \times 1,0 \mathrm{~m}$, lançado quatro vezes aleatoriamente nas áreas, para estimar a quantidade de cobertura morta existente $\left(\mathrm{em} \mathrm{kg} \mathrm{ha}^{-1}\right)$. Os materiais contidos nos quadros foram cortados rente ao solo, acondicionados em saco de papel e levados para secagem em estufa de circulação forçada de ar, em temperatura de $70{ }^{\circ} \mathrm{C}$, até massa seca constante, para determinação da matéria seca. Em Colina, U. ruziziensis representava $100 \%$ da cobertura vegetal do solo, enquanto em Jaboticabal correspondeu a mais de $80 \%$, com ocorrência de algumas plântulas de Indigofera hirsuta (anileira), Conyza canadensis (buva) e Phyllanthus tenellus (quebra-pedra), que foram retiradas manualmente da área experimental. No momento da coleta, em Colina, as plantas de $U$. ruziziensis encontravam-se em média com 0,6 a 0,7 m de altura, e em Jaboticabal apresentavam-se menores: com 0,3 a $0,4 \mathrm{~m}$.

Em Colina, foram testados quatro períodos de dessecação antecedendo a semeadura da soja: 30, 20, 10 e 0 dias. Para o experimento em Jaboticabal, os tratamentos corresponderam a seis períodos de dessecação antecedendo a semeadura da soja: 25, 20, 16, 12, 7 e 0 dias.

Nos dois experimentos utilizou-se 1,440 kg e.a. ha-1 do herbicida glyphosate para a dessecação, empregando-se um pulverizador costal de precisão, munido de barra com seis pontas de jato plano (TT 110.02), espaçadas de 
$0,5 \mathrm{~m}$, com consumo de calda equivalente a $200 \mathrm{~L} \mathrm{ha}^{-1}$ e pressão constante de $2,24 \mathrm{kgf} \mathrm{cm}^{-2}$.

Os dois experimentos foram instalados sobre um Latossolo Vermelho Eutrófico típico de textura argilosa. Com base em análise de solo e na necessidade nutricional da cultura, realizou-se adubação, que constituiu de aplicação de $270 \mathrm{~kg} \mathrm{ha}^{-1}$ da formulação 02-20-20 (N-P-K) no sulco de semeadura. O cultivar de soja utilizado foi o M-SOY 7908 RR, semeado em um único período, nos respectivos anos. As sementes, em ambos os experimentos, foram tratadas quimicamente com thiram e, na sequência, submetidas à inoculação com Bradyrhizobium japonicum. A semeadura foi feita mecanicamente, com espaçamento entre linhas de $0,45 \mathrm{~m}$, a uma profundidade de $5 \mathrm{~cm}$. Foram distribuídas 23 sementes por metro.

No decorrer do período experimental foram tomadas todas as medidas preventivas $\mathrm{e}$ curativas, visando à boa sanidade da cultura. Quanto ao manejo das plantas daninhas, foi realizada uma única aplicação de glyphosate no estádio V2 da cultura da soja, na dose de 1.080 g e.a. ha ${ }^{-1}$.

O delineamento experimental utilizado, nos dois experimentos, foi o de blocos ao acaso, com quatro repetições. As parcelas experimentais foram dimensionadas em $10 \times 6 \mathrm{~m}$, tomando-se como área útil cinco linhas centrais, excluindo um metro de cada extremidade, totalizando $18 \mathrm{~m}^{2}$.

Aos 20 dias após a semeadura (DAS) da soja foi determinado o estande inicial, contandose as plantas encontradas dentro da área útil de cada parcela.

Por ocasião da colheita da soja (120 DAS) foi retirada, de cada parcela, uma amostra de plantas de soja presentes em 0,5 $\mathrm{m}$ da linha de semeadura, que correspondeu a 10 plantas de soja, para determinação da altura, da altura de inserção da primeira vagem e do número de vagens por planta. Para a produtividade de grãos da cultura, coletaram-se manualmente todas as plantas de soja presentes na área útil de cada parcela $\left(18 \mathrm{~m}^{2}\right)$ e, em seguida, trilharam-se as plantas mecanicamente, para obtenção dos grãos. Para expressão da produtividade, a massa de grãos foi corrigida para $13 \%$ de umidade.
Os resultados foram submetidos à análise de variância pelo teste $\mathrm{F}$, com as médias sendo comparadas pelo teste de Tukey a $5 \%$ de probabilidade; realizou-se análise de regressão com os resultados de produtividade de grãos.

Foram coletados os dados de precipitação pluvial e temperatura média na Estação Agroclimatológica do Departamento de Ciências Exatas da FCAV/UNESP, campus de Jaboticabal, e na Estação Climatológica de Colina, ambos acumulados durante os períodos em que se realizou a dessecação da cobertura vegetal de $U$. ruziziensis, antecedendo a semeadura da soja (Figura 1).

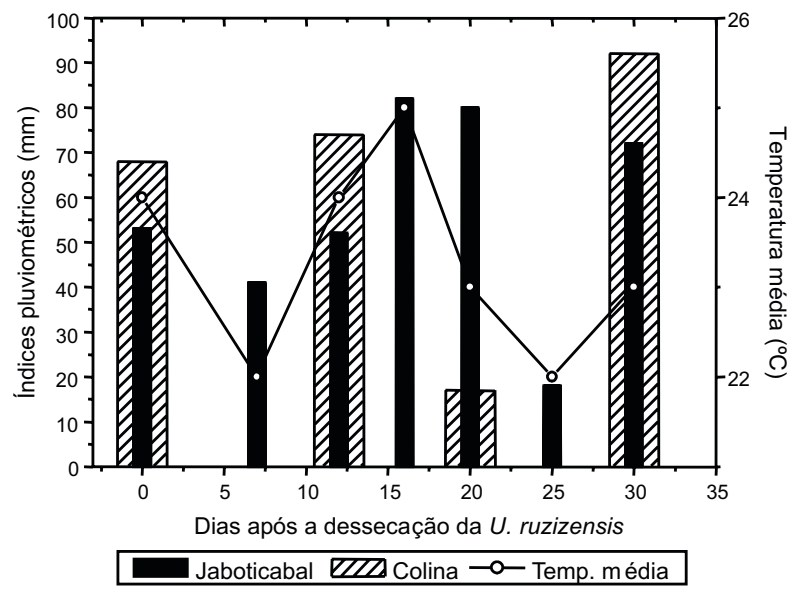

Figura 1 - Índices pluviométricos e temperatura média da área de Colina (2007/08) e Jaboticabal (2009/10), durante os períodos em que se realizou a dessecação de $U$. ruziziensis com glyphosate, antecedendo a semeadura da soja. Jaboticabal, 2010

\section{RESULTADOS E DISCUSSÃO}

Em Colina, após a dessecação com glyphosate, houve formação de uma camada de $U$. ruziziensis morta sobre o solo de, aproximadamente, $16 \mathrm{~cm}$ de espessura, correspondendo a $10 \mathrm{t} \mathrm{ha}^{-1}$ de massa seca. Em Jaboticabal, a cobertura de $U$. ruziziensis dessecada correspondeu a 6,0 t ha ${ }^{-1}$. Essa menor quantidade de massa seca em Jaboticabal foi consequência do menor desenvolvimento de Urochloa e também do não recobrimento total do solo, próximo a $80 \%$. Mesmo com essa diferença na quantidade e espessura da cobertura morta sobre o solo formada nos dois experimentos, não se constatou efeito significativo 
sobre o estande da soja aos 20 dias após a semeadura (Tabela 1). Esses resultados diferem dos encontrados por Oliveira Júnior et al. (2006), pois, segundo esses autores, houve efeitos negativos da dessecação de uma cobertura de plantas daninhas, com predominância de $80 \%$ de Bidens pilosa, no estande da soja aos 30 dias após a semeadura, porém esses efeitos não afetaram de forma significativa os componentes produtivos da soja.

No experimento em Colina, verificou-se efeito do período de dessecação (manejo) na altura de plantas (Tabela 2), e ocorreu redução significativa de $6,3 \%$ com a semeadura 0 dia após a aplicação - DAA (aplique e plante), comparado ao manejo de 10 DAA - esta última

Tabela 1 - Estande da soja (plântulas $\mathrm{m}^{-1}$ ) aos 20 dias após a sua semeadura em Colina e Jaboticabal, em função dos períodos de dessecação de $U$. ruziziensis

\begin{tabular}{|c|c|c|c|c|c|}
\hline Local & $\mathrm{DAA}^{1 /}$ & Estande & Local & DAA & Estande \\
\hline \multirow{6}{*}{ Colina } & & & \multirow{6}{*}{ Jaboticabal } & 25 & $14,90 \mathrm{~A}$ \\
\hline & 30 & $16,50 \mathrm{~A}$ & & 20 & $15,80 \mathrm{~A}$ \\
\hline & 20 & $16,10 \mathrm{~A}$ & & 16 & $15,60 \mathrm{~A}$ \\
\hline & 10 & $15,78 \mathrm{~A}$ & & 12 & $14,7 \mathrm{~A}$ \\
\hline & 0 & $15,72 \mathrm{~A}$ & & 7 & $15,10 \mathrm{~A}$ \\
\hline & & & & 0 & $15,3 \quad \mathrm{~A}$ \\
\hline \multicolumn{2}{|c|}{ F bloco } & \multicolumn{2}{|c|}{$2,29^{\mathrm{NS}}$} & & $1,08^{\mathrm{NS}}$ \\
\hline \multicolumn{2}{|c|}{ F trat. } & \multicolumn{2}{|c|}{$3,39^{\mathrm{NS}}$} & & $1,29^{\mathrm{NS}}$ \\
\hline \multicolumn{2}{|c|}{$\mathrm{DMS}$} & \multicolumn{2}{|c|}{0,816} & & 2,67 \\
\hline \multicolumn{2}{|c|}{$\mathrm{CV}(\%)$} & \multicolumn{2}{|c|}{2,71} & & 5,12 \\
\hline
\end{tabular}

$\mathrm{DAA}^{1 /}=$ dias após a aplicação, Médias seguidas por mesma letra, na coluna, não diferem entre si pelo teste de Tukey a $5 \%$ de probabilidade. ${ }^{N S}$ não significativo pelo teste $\mathrm{F}$. adotada como padrão devido ao melhor desempenho observado para produtividade de grãos (Tabela 2). Efeito semelhante em altura de plantas foi observado no experimento em Jaboticabal, com redução média de $10 \%$, adotando-se como padrão o manejo de 12 DAA (Tabela 3 ). A redução mais acentuada na altura de plantas de soja em Colina no manejo de 0 DAA deve-se, provavelmente, ao efeito da quantidade de cobertura morta disposta sobre o solo, que foi $40 \%$ maior quando comparada à de Jaboticabal. Em relação a esse fato, inferese também uma possivel maior concentração de aleloquímicos solúveis em água, presentes na solução do solo, provenientes da forrageira, uma vez que a concentração de aleloquímicos é dependente da quantidade de resíduos vegetais no solo (Machado \& Assis, 2010); ressaltase que existem vários fatores que também influenciam a concentração de aleloquímicos nas plantas (Gobbo-Neto \& Lopes, 2007).

Tanto no experimento em Colina quanto no de Jaboticabal não houve diferença significativa para altura de inserção da primeira vagem de soja nos manejos avaliados (Tabelas 2 e 3, respectivamente). Resultados semelhantes foram apresentados por Nunes et al. (2009), ao trabalharem com períodos de manejo químico de Brachiaria decumbens antecedendo a semeadura direta em dois cultivares de soja convencional.

O número de vagens por planta, em Colina, apresentou redução de $12,7 \%$ com o manejo de 0 DAA (aplique e plante), comparado ao manejo de 10 DAA - este último adotado como

Tabela 2 - Efeito dos períodos de dessecação de U. ruziziensis sobre altura de plantas, altura de inserção da primeira vagem, número de vagens por planta em $0,5 \mathrm{~m}^{2}$ e produtividade dos grãos de soja estimada em $\mathrm{kg} \mathrm{ha}^{-1}$. Colina-SP, 2008/09

\begin{tabular}{|c|c|c|c|c|c|}
\hline $\begin{array}{c}\text { Cobertura } \\
\text { vegetal }\end{array}$ & $\begin{array}{l}\text { Período dessec. } \\
\text { (DAA) }\end{array}$ & $\begin{array}{l}\text { Altura de plantas } \\
(\mathrm{cm})\end{array}$ & $\begin{array}{l}\text { Altura de inserção } \\
\text { da } 1^{\text {a }} \text { vagem }(\mathrm{cm})\end{array}$ & $\begin{array}{c}\mathrm{N}^{\mathrm{o}} \text { de vagens por } \\
\text { planta }\end{array}$ & $\begin{array}{l}\text { Produtividade } \\
\quad\left(\mathrm{kg} \mathrm{ha}^{-1}\right)\end{array}$ \\
\hline \multirow{4}{*}{ Urochloa } & 30 & $70,30 \mathrm{~A}^{\mathrm{1}^{\prime}}$ & $25,90 \mathrm{~A}$ & $35,20 \mathrm{~A}$ & $3.006 \mathrm{~A}$ \\
\hline & 20 & $64,23 \mathrm{BC}$ & $23,47 \mathrm{~A}$ & $34,90 \mathrm{~A}$ & $3.143 \mathrm{~A}$ \\
\hline & 10 & $66,63 \mathrm{AB}$ & $22,83 \mathrm{~A}$ & $31,30 \mathrm{AB}$ & $3.160 \mathrm{~A}$ \\
\hline & 0 & $62,37 \mathrm{C}$ & $22,70 \mathrm{~A}$ & $27,30 \mathrm{~B}$ & $2.180 \mathrm{~B}$ \\
\hline \multicolumn{2}{|c|}{ F bloco } & $1,41^{\mathrm{NS}}$ & 1,32 & $2,3^{\mathrm{NS}}$ & $5,41 *$ \\
\hline \multicolumn{2}{|c|}{ F trat. } & $17,27^{* *}$ & 1,08 & $5,00^{*}$ & $7,62 * *$ \\
\hline \multicolumn{2}{|c|}{ DMS } & 4,15 & 2,72 & 7,23 & 55,16 \\
\hline \multicolumn{2}{|c|}{$\mathrm{CV}(\%)$} & 3,74 & 6,12 & 13,48 & 6,11 \\
\hline
\end{tabular}

${ }^{1 /}$ Médias seguidas por mesma letra, na coluna, não diferem entre si pelo teste de Tukey a $5 \%$ de probabilidade. ${ }^{\text {Ns }}$ não significativo pelo teste $\mathrm{F} ; * *$ diferem em $1 \% ; *$ diferem em $5 \%$ de probabilidade. DAA = dias após a aplicação do glyphosate. 
Tabela 3 - Efeito dos períodos de dessecação de U. ruziziensis sobre altura de plantas, altura de inserção da primeira vagem, número de vagens por planta em $0,5 \mathrm{~m}^{2}$ e produtividade dos grãos de soja estimada em $\mathrm{kg} \mathrm{ha}^{-1}$. Jaboticabal, 2009/10

\begin{tabular}{|c|c|c|c|c|c|}
\hline $\begin{array}{c}\text { Cobertura } \\
\text { vegetal }\end{array}$ & $\begin{array}{c}\text { Período dessec. } \\
\text { (DAA) }\end{array}$ & $\begin{array}{l}\text { Altura de plantas } \\
(\mathrm{cm})\end{array}$ & $\begin{array}{l}\text { Altura de inserção } \\
\text { da } 1^{\text {a }} \text { vagem }(\mathrm{cm})\end{array}$ & $\begin{array}{c}\text { № de vagens por } \\
\text { planta }\end{array}$ & $\begin{array}{l}\text { Produtividade } \\
\left(\mathrm{kg} \mathrm{ha}^{-1}\right)\end{array}$ \\
\hline \multirow{6}{*}{ Urochloa } & 25 & $76,76 \mathrm{AB}^{1 / /}$ & $23,02 \mathrm{~A}$ & $37,07 \mathrm{AB}$ & $3.290 \mathrm{~B}$ \\
\hline & 20 & $79,89 \mathrm{~A}$ & $23,61 \mathrm{~A}$ & $40,50 \mathrm{~A}$ & $3.445 \mathrm{AB}$ \\
\hline & 16 & $79,31 \mathrm{~A}$ & $22,14 \mathrm{~A}$ & $40,62 \mathrm{~A}$ & $3.545 \mathrm{~A}$ \\
\hline & 12 & $79,35 \mathrm{~A}$ & $22,85 \mathrm{~A}$ & $39,37 \mathrm{AB}$ & $3.542 \mathrm{~A}$ \\
\hline & 7 & $76,20 \mathrm{AB}$ & $22,83 \mathrm{~A}$ & $33,80 \mathrm{~B}$ & $3.290 \mathrm{~B}$ \\
\hline & 0 & $71,20 \quad \mathrm{~B}$ & $21,75 \mathrm{~A}$ & $32,66 \mathrm{~B}$ & $3.288 \mathrm{~B}$ \\
\hline \multicolumn{2}{|c|}{ F bloco } & $0,71^{\mathrm{NS}}$ & $1,08^{\mathrm{NS}}$ & $1,44^{\mathrm{NS}}$ & $0,26^{\mathrm{NS}}$ \\
\hline \multicolumn{2}{|c|}{ F trat. } & $3,54 *$ & $1,29^{\mathrm{NS}}$ & $5,07 * *$ & $7,58 * *$ \\
\hline \multicolumn{2}{|c|}{ DMS } & 7,849 & 2,674 & 6,39 & 207,54 \\
\hline \multicolumn{2}{|c|}{$\mathrm{CV}(\%)$} & 4,43 & 5,12 & 9,76 & 2,66 \\
\hline
\end{tabular}

${ }^{1 /}$ Médias seguidas por mesma letra, na coluna, não diferem entre si pelo teste de Tukey a $5 \%$ de probabilidade. ${ }^{\text {Ns }}$ não significativo pelo teste $\mathrm{F} ; * *$ diferem em $1 \%$; *diferem em $5 \%$ de probabilidade. DAA - dias após a aplicação do glyphosate.

padrão (Tabela 2). Para Jaboticabal, esse componente produtivo apresentou redução significativamente de 17 e $14 \%$ com os manejos aos 0 e 7 DAA, respectivamente (Tabela 3), quando comparado ao manejo de 12 DAA. A redução ocorrida no número de vagens por planta aos 0 e 7 DAA deve-se, possivelmente, como ocorreu em altura de plantas, à concentração de aleloquímicos, que estavam disponíveis na solução do solo.

Em Colina, a produtividade de grãos da soja $\left(\mathrm{kg} \mathrm{ha}^{-1}\right)$ foi reduzida em $31 \%$ ao 0 DAA, que correspondeu à aplicação de glyphosate no dia da semeadura da soja, quando comparada à do manejo de $10 \mathrm{DAA}$, adotado como padrão (Tabela 2). Já no experimento de Jaboticabal a produtividade de grãos foi reduzida em $7,1 \%$ com a dessecação aos 0 e 7 DAA, quando comparado ao manejo de 12 DAA, adotado como padrão (Tabela 3). A acentuada diferença detectada na produtividade de grãos ao 0 DAA entre Colina e Jaboticabal deve-se, possivelmente, à quantidade de cobertura vegetal de Urochloa presente nas áreas, pois, em Colina, onde houve maior redução de produtividade (31\%), a cobertura vegetal foi $40 \%$ superior à de Jaboticabal; isso provavelmente também esteja relacionado com alguns aleloquímicos presentes na Urochloa, que foram lixiviados pelas chuvas (Figura 1) e carreados para a solução do solo, atingindo concentrações suficientes para afetar negativamente a cultura da soja. Sabe-se que chuvas continuas podem resultar na perda de substâncias hidrossolúveis das folhas e raízes por lixiviação, e isso se aplica a algumas plantas produtoras de alcaloides, glicosídeos e até mesmo óleos voláteis (Waterman \& Moles, 1994; Evans, 1996). Para Putnam \& Duke (1978), os aleloquímicos, para atuarem sobre os organismos, necessitam atingir a concentração mínima no meio, às quais eles são suscetíveis.

Efeitos inibitórios sobre várias características agronômicas na cultura da soja como consequência da dessecação de Brachiaria spp. em períodos próximos à semeadura da soja também foram encontrados por Santos et al. (2007) e Nunes et al. (2009), corroborando os dados observados nesta pesquisa. Esses autores concluíram que o período mais adequado para o manejo químico de $B$. ruziziensis e $B$. decumbens situa-se entre 7 e 14 dias antes da semeadura da soja, respectivamente. Silva et al. (2006) sugeriram que a dessecação de $B$. brizantha deve ser feita em periodos iguais ou maiores que 14 dias antes da semeadura da soja.

Maciel et al.(2003) observaram resultados semelhantes quanto a área foliar, matéria seca e razão da área foliar em soja quando utilizaram dois manejos: com palha de $U$. decumbens em superficie + irrigação superficial e com 
palha em superfície + irrigação subsuperficial. Esses autores relataram que, como o efeito foi praticamente idêntico nos dois manejos, descartaram a hipótese da lixiviação de compostos químicos presentes na palhada via irrigação. Uma provável explicação para essas respostas semelhantes com a adoção de diferentes manejos é que os autores não consideraram o periodo compreendido entre a dessecação de $U$. decumbens e a coleta do material no campo, que foi de 30 dias após a dessecação; nesse período, pode ter ocorrido a lixiviação de substâncias alelopáticas hidrossolúveis contidas em $U$. decumbens, por chuva e/ou orvalho.

Quando se analisa a redução de produtividade de grãos da soja ocorrida em Colina com o manejo ao O DAA (31\%) e em Jaboticabal ao 0 e 7 DAA $(7,1 \%$, em média), esses resultados mostram uma possivel existência de aleloquímicos liberados por $U$. ruziziensis durante esses períodos e que a intensidade do efeito negativo foi maior em Colina devido à maior quantidade de cobertura vegetal (10 t ha $\mathrm{h}^{-1}$ ), enquanto em Jaboticabal ela correspondeu a $6 \mathrm{t} \mathrm{ha}^{-1}$; atrelado a esse efeito da quantidade de cobertura, as chuvas ocorridas nesses períodos, que ultrapassaram os $80 \mathrm{~mm}$ dos 0 aos 7 DAA (Figura 1), podem ter auxiliado na lixiviação de aleloquímicos hidrossolúveis contidos na $U$. ruziziensis.

Deve-se lembrar que o efeito negativo observado, de modo geral, sobre os componentes de produtividade da soja devido à cobertura vegetal pode também estar relacionado com a relação $\mathrm{C} / \mathrm{N}$. A menor intensidade do efeito negativo nos componentes produtivos da soja em Jaboticabal pode ser atribuída à menor quantidade de cobertura vegetal depositada sobre o solo, que, consequentemente, interferiu menos na dinâmica do nitrogênio disponível às plantas. Souza et al. (2006), avaliando os efeitos alelopáticos de $B$. decumbens sobre o crescimento inicial de milho, arroz, trigo, soja, feijão e algodão e a dinâmica do nitrogênio no solo, concluíram que a incorporação da matéria seca da parte aérea de $B$. decumbens reduziu significativamente os teores de nitrato no solo em todos os estudos realizados. Entretanto, segundo Maciel et al. (2003), esses efeitos não são observados quando se adota o sistema de plantio direto.
Em trabalho realizado por Oliveira Júnior et al. (2006), o controle de Bidens pilosa realizado na data da semeadura da soja ou dez dias antes prejudicou o desenvolvimento da cultura, resultando em queda na produtividade entre 10 e $20 \%$, se comparado ao manejo químico realizado aos 20 dias antes da semeadura. Ainda segundo esses autores, os métodos de controle complementar (manual, aplicação sequencial ou em dose única de herbicidas após a emergência da cultura) proporcionaram incremento de produtividade em relação à não realização do controle, o que reflete a interferência imposta pelas plantas daninhas na soja.

Foi realizada a estimativa do intervalo favorável, em função da significância dos dados observados para a produtividade de grãos, entre a dessecação de Urochloa e a semeadura da soja. Em Jaboticabal, esse intervalo situou-se entre 10 e 21 dias, sendo a produção máxima de $3.540 \mathrm{~kg} \mathrm{ha}^{-1}$ obtida aos $12 \mathrm{DAA}$ e a estimada de $3.587 \mathrm{~kg} \mathrm{ha}^{-1}$ aos 14 DAA (Figura 2). Quando a semeadura foi realizada aos 0,7 e 25 dias após a dessecação de Urochloa, ocorreu efeito negativo na produtividade, com perda média de $7,1 \%$ na produção de grãos. Para Colina, esse intervalo situou-se entre 8 e 24 dias, com produção máxima obtida de $3.142 \mathrm{~kg} \mathrm{ha}^{-1}$ aos 10 DAA e estimada de $3.223 \mathrm{~kg} \mathrm{ha}^{-1}$ aos 14 DAA (Figura 3). Quando a

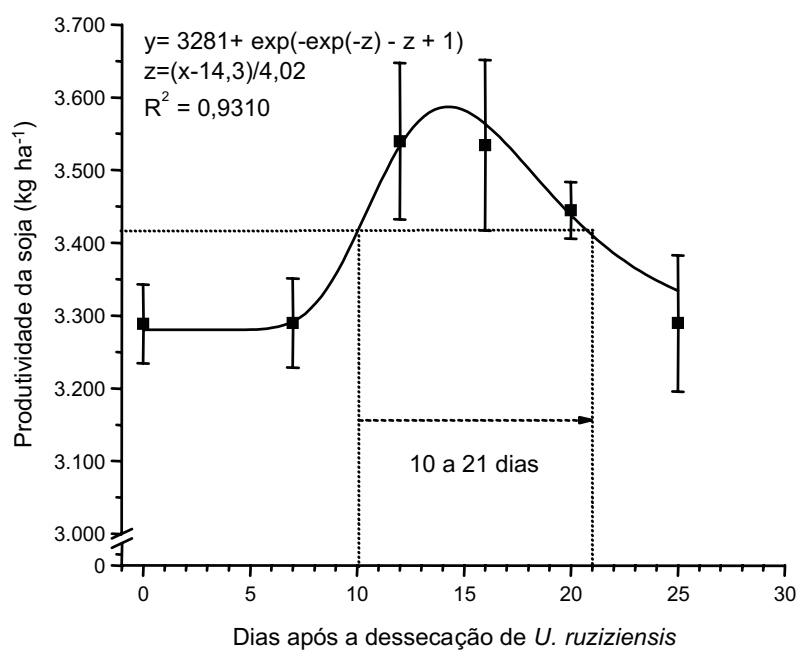

Figura 2 - Produtividade da soja ( $\left.\mathrm{kg} \mathrm{ha}^{-1}\right)$, em Jaboticabal-SP (2009/10), relacionada com os períodos de dessecação, com glyphosate, de $U$. ruziziensis, antecedendo a semeadura da soja.

Planta Daninha, Viçosa-MG, v. 30, n. 3, p. 557-565, 2012 


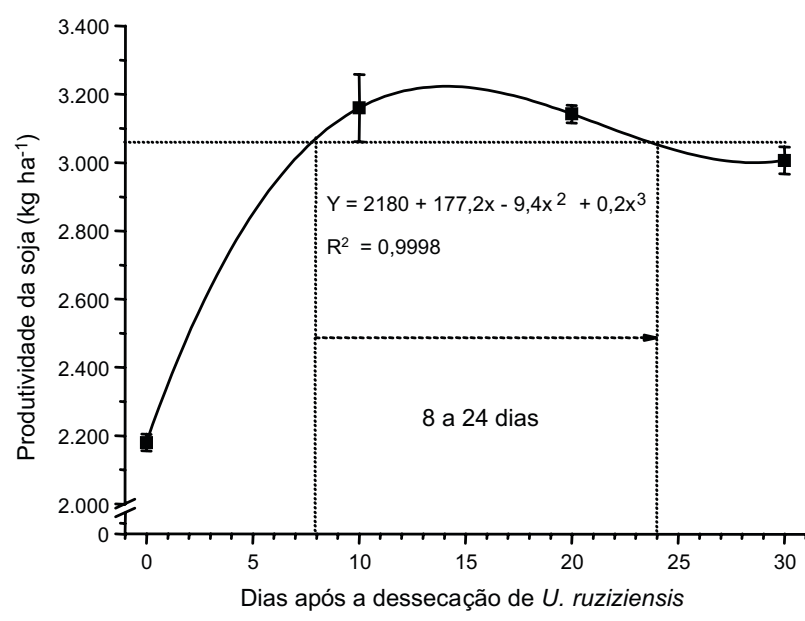

Figura 3 - Produtividade da soja ( $\mathrm{kg} \mathrm{ha}^{-1}$ ), em Colina-SP (2008/ 9), relacionada com os períodos de dessecação, com glyphosate, de U. ruziziensis, antecedendo a semeadura da soja.

semeadura da soja foi feita zero dia após a dessecação de Urochloa, houve redução de 31\% na produtividade da cultura.

Nas condições em que foi realizada esta pesquisa, conclui-se que para utilização de uma área com cobertura vegetal de $U$. ruziziensis é recomendável semear a soja em um período compreendido entre 10 e 20 dias após a dessecação da forrageira com glyphosate.

\section{AGRADECIMENTOS}

À FAPESP, pela concessão de bolsa DR para M. P. Nepomuceno, e ao CNPq, pela concessão de bolsa $P Q$ para P.L.C.A. Alves.

\section{LITERATURA CITADA}

BARNES, J. P.; PUTNAM, A. R. Rye residues contribute weed suppression in no-tillage cropping systems. Chem. Ecol., v. 9, n. 8, p. 1045-1057, 1983.

BAYER, C. et al. Carbon sequestration in two Brazilian Cerrado soils under no-till. Soil Tillage Res., v. 86, n. 2, p. 237-245, 2006.

CHOU, C. H.; PATRICK, Z. A. Identification and phytotoxic activity of coumpounds produced during decomposition of corn and rye residues in soil. J. Chem. Ecol., v. 2, n. 3, p. 369-387, 1976.

DUDA, G. P. et al. Perennial herbaceous legumes as live soil mulches and their effects on $\mathrm{C}, \mathrm{N}$ and $\mathrm{P}$ of the microbial biomass. Sci. Agric., v. 60, n. 1, p. 139-147, 2003.
EMPRESA BRASILEIRA DE PESQUISA

AGROPECUÁRIA - EMBRAPA. Tecnologias de

Produção de Soja. Londrina: 2004. 239 p.

EVANS, W. C. Trease and evans' pharmacognosy, 14.ed. London: WB Saunders Company, 1996. cap. 7.

FERRAZ, F. M. Pastagens garantem o futuro da agropecuária brasileira. In: NAKAMAE, I. J. (Ed.). Anualpec - Anuário da pecuária brasileira. São Paulo: FNP Consultoria e Agroinformativos, 2003. p. 55-56.

GOBBO-NETO, L.; LOPES, N. P. Plantas medicinais: fatores de influência no conteúdo de metabólicos secundários. Química Nova, v. 30, n. 2, p. 374-381, 2007.

MACHADO, L. A. Z.; ASSIS, P. G. Produção de palha e forragem por espécies anuais e perenes em sucessão à soja Pesq. Agropec. Bras., v. 45, n. 4, p. 415-422, 2010.

MACIEL, C. D. G. et al. Influência do manejo da palhada de capim-braquiária (Brachiaria decumbens) sobre o desenvolvimento inicial de soja (Glycine max) e amendoimbravo (Euphorbia heterophylla). Planta Daninha, v. 21, n. 3, p. 365-373, 2003.

MENEZES, L. A. S. et al. Produção de fitomassa de diferentes espécies, isoladas e consorciadas, com potencial de utilização para cobertura do solo. Biosci. J., v. 25, n. 1, p. 7-12, 2009.

MELHORANÇA, A. L.; VIEIRA, C. P. Efeito da época de dessecação sobre o desenvolvimento e produção da soja. In: REUNIÃO DE PESQUISA DE SOJA DA REGIÃO CENTRAL DO BRASIL, 21., 1999, Dourados. Resumos... Dourados: Embrapa Agropecuária Oeste, 1999. p. 224-225.

MURAISHI, C. T. et al. Manejo de espécies vegetais de cobertura do solo e produtividade do milho e da soja em semeadura direta. Acta Sci. Agron., v. 27, p. 199-207, 2005.

NUNES, A. S. et al. Épocas de manejo químico de Brachiaria decumbens antecedendo o plantio direto de soja

Planta Daninha, v. 27, n. 2, p. 297-302, 2009.

NUNES, U. R. et al. Produção de palhada de plantas de cobertura e rendimento do feijão em plantio direto. Pesq. Agropec. Bras., v. 41, n. 6, p. 943-948, 2006.

OLIVEIRA, T. K.; CARVALHO, G. J.; MORAES, R. N. S. Plantas de cobertura e seus efeitos sobre o feijoeiro em plantio direto. Pesq. Agropec. Bras., v. 37, n. 8, p. 1079-1087, 2002.

OLIVEIRA JÚNIOR, R. S. et al. Interação entre sistemas de manejo e de controle de plantas daninhas em pós-emergência afetando o desenvolvimento e a produtividade da soja.

Planta Daninha, v. 24, n. 4, p. 721-732, 2006. 
PACHECO, L. P. et al. Desempenho de plantas de cobertura em sobressemeadura na cultura da soja. Pesq. Agropec. Bras., v. 43, n. 7, p. $815-823,2008$

PUTNAM, A. R.; DUKE, W. D. Allelopathy in agroecossystems. Ann. Rev. Phytopath., v. 16, n. 16, p. $431-451,1978$.

SANTOS, J. B. et al. Época de dessecação anterior a semeadura sobre o desenvolvimento da soja resistente ao glyphosate. Planta Daninha, v. 25, n. 4, p. 869-875, 2007.

SILVA, A. C. et al. Micorrização e épocas de dessecação de Brachiaria brizantha no desenvolvimento da soja.

Planta Daninha, v. 24, n. 2, p. 271-277, 2006.
SOUZA, L. S. et al. Efeito alelopático de capim-braquiária (Brachiaria decumbens) sobre o crescimento inicial de sete espécies de plantas cultivadas. Planta Daninha, v. 24, n. 4, p. 657-668, 2006.

TORRES, J. L. R.; PEREIRA, M. G.; FABIAN, A. J. Produção de fitomassa por plantas de cobertura e mineralização de seus resíduos em plantio direto. Pesq. Agropec. Bras., v. 43, n.3, p. 421-428, 2008.

WATERMAN, P. G.; MOLE, S. Analysis of phenolic plant metabolites. Oxford, Blackwell Scientific Publications, 1994. $238 \mathrm{p}$. 